\title{
Protective Effects of Zinc Supplementation on Renal Toxicity in Rats Exposed to Cadmium
}

\author{
Raziyeh Morshedi ${ }^{1}$; Massumeh Ahmadizadeh ${ }^{1,2,} ;$ Kambiz Ahmadi Angali $^{3}$ \\ ${ }^{1}$ Department of Occupational Health Engineering, School of Health, Ahvaz Jundishapur University of Medical Sciences, Ahvaz, IR Iran \\ ${ }_{2}^{2}$ Physiology Research Center, Ahvaz Jundishapur University of Medical Sciences, Ahvaz, IR Iran \\ 3 Department of Statistics and Epidemiology, School of Health, Ahvaz Jundishapur University of Medical Sciences, Ahvaz, IR Iran \\ ${ }^{*}$ Corresponding author: Massumeh Ahmadizadeh, Department of Occupational Health Engineering, School of Health, Ahvaz Jundishapur University of Medical Sciences, Ahvaz, IR \\ Iran. Tel: +98-6113738269, Fax:+98-6113738282, E-mail: ahmadizadeh_m@ajums.ac.ir
}

Received: April 21, 2014; Revised: May 25, 2014; Accepted: June 2, 2014

\begin{abstract}
Background: Cadmium (Cd) is a nonessential element with many industrial applications and is one of the most toxic pollutants in the environment. The ultimate goal of occupational health is prevention of health hazards on workplace; hence, is as a hazardous chemical contaminant in the workplace, $\mathrm{Cd}$ needs special attention.

Objectives: The object of this study was to determine the effect of $\mathrm{ZnCl}_{2}$ on Cd-induced nephrotoxicity in rats.

Materials and Methods: Adult male rats were given $\mathrm{CdCl}_{2}$ at doses of $0,1,2$, and $3 \mathrm{mg} / \mathrm{kg}$. Another series of rats were pretreated with $4 \mathrm{mg} /$ $\mathrm{kg}$ of $\mathrm{ZnCl}_{2} 30$ minutes prior to administration of various doses of $\mathrm{CdCl}_{2}$. The experiment was repeated for seven consecutive days. Twentyfour hours after administering the latest dose, animals were sacrificed. Blood samples were analyzed for blood urea nitrogen (BUN) and creatinine levels. Kidney tissues were excised for measuring malondialdehyde(MDA) concentration.

Results: In contrast to the animals that received $\mathrm{ZnCl} 2, \mathrm{CdCl}_{2}$ induced a dose-dependent elevation in BUN, creatinine, and MDA in those without $\mathrm{ZnCl} 2$ pretreatment. Zinc chloride had significantly decreased all biochemical parameters and protected kidney cells against Cdinduced toxicity.

Conclusions: The results of this study supported the potential protective effects of $\mathrm{ZnCl}_{2}$ on rat kidney tissues against $\mathrm{CdCl}_{2}$ toxicity.

Keywords:Zinc Chloride; Cadmium Chloride; Malondialdehyde; Kidney; Rat
\end{abstract}

\section{Background}

Cadmium (Cd) is an environmental and industrial pollutant that can cause a broad spectrum of adverse effects on various organs in humans and animals (1). It is used in plating industries such as steel, stabilized production of polyvinyl chloride (PVC), plastics and glass dyeing, and in the manufacture of nickel-cadmium batteries (2). Generally, Cd is a nonessential element for the human body that has toxic effects on organs (3). The studies have shown that not only occupationally Cd-exposed workers but also environmentally Cd-exposed population experience health problems (4). Unfortunately, human occupational and environmental contact with $\mathrm{Cd}$ is an inevitable consequence and Cd causes adverse effects on different organs and tissues (5). Environmental contact with Cd occurs mainly through contaminated food and water consumption and passive smoking (6). The kidneys are the main target organs of Cd. After absorption, Cd is distributed in various tissues. Long-term exposure to Cd leads to its accumulation, particularly in the liver and kidneys, metabolic and histological changes, and damage to the cell membrane (7). It is excreted very slowly through the kidneys with a half-life of 15 to 20 years (8). Long-term exposure to Cd can cause nephrotoxicity in humans; studies in rats have shown that Cd compounds can cause nephrotoxicity. Gen- erally, toxic effects of Cd are due to producing oxidative stress and interfering with essential elements, especially zinc ( $\mathrm{Zn}$ ) (9). The researchers found that vitamin $C$ and selenium would protect kidneys of rats who received $\mathrm{Cd}$ (10). As a vital element, $\mathrm{Zn}$ is involved in metabolic activities (11). Recently, it was reported that zinc chloride $\left(\mathrm{ZnCl}_{2}\right)$ has protective effect on cobalt chloride-induced cytotoxicity in the kidney cells (12). In addition, Zn prevents the toxic effects of lead $(\mathrm{Pb})$ in embryonic epithelium of rats (13). It appears that the beneficial effects of $\mathrm{Zn}$ are associated with its role in metallothionein (Mt) biosynthesis (11). Cd intoxication causes a dose-dependent increase in blood urea nitrogen (BUN) and creatinine $(\mathrm{Cr})$ in rats. The administration of selenium and vitamin $\mathrm{C}$ can reduce BUN and $\mathrm{Cr}$ in rats (10). To our knowledge, the effect of $\mathrm{Zn}$ on $\mathrm{Cd}$ has not been reported extensively (14). Since Cd is a hazardous chemical contaminant in the workplace, it needs specific consideration as the ultimate goal of occupational health is prevention of health hazards in the workplace.

\section{Objectives}

The aim of the present study was to determine the effect $\mathrm{ZnCl}_{2}$ on Cd-induced nephrotoxicity in rat.

Copyright @ 2014, Ahvaz Jundishapur University of Medical Sciences; Published by Kowsar Corp. This is an open-access article distributed under the terms of the Creative Commons Attribution License, which permits unrestricted use, distribution, and reproduction in any medium, provided the original work is properly cited. 


\section{Materials and Methods}

All reagents and chemicals were of analytical grade or higher purity. Cadmium chloride $\left(\mathrm{CdCl}_{2}\right)$ and $\mathrm{ZnCl}_{2}$ were obtained from Merck (Darmstadt, Germany).

\subsection{Animal Treatments}

Adult male Wistar rats (250-300 g) were housed in groups of three in clear polypropylene cages in a light cycle (12 hours light and 12 hours dark) and temperaturecontrolled room. The animals were allowed food and tap water ad libitum. For treatment group animals, $4 \mathrm{mg} /$ $\mathrm{kg}$ of $\mathrm{ZnCl}_{2}$ was injected intraperitoneally. Control rats received vehicle only. Thirty minutes later, animals were given $0,1,2$, and $3 \mathrm{mg} / \mathrm{kg}$ of $\mathrm{CdCl}_{2}$. The experiment was repeated for seven consecutive days. Twenty-four hours after last treatment, all animals were sacrificed with over dose of sodium pentobarbital. Blood samples were collected for measuring BUN and Cr. Kidney tissue were excised and processed for assessing malondialdehyde (MDA) content. Kidney tissue from each rat was homogenized by four minutes centrifugation at $10000 \times \mathrm{g}$ in ten volumes of precooled phosphate buffered saline $(0.1 \mathrm{M}$; $\mathrm{pH}$ 7.4). Then the homogenate was centrifuged at 3000 $\times \mathrm{g}$ for ten minutes to collect the supernatant for MDA assays. MDA level was estimated by Satoh method (15). In this measurement, the principle method was spectrophotometric color measurement, which was estimated calorimetrically by measuring thiobarbituric acid reactive substances (TBARS). The protocol was approved by the Ethics Committee of the Ahvaz Jundishapur University of Medical Sciences. Biochemical data were expressed as mean \pm standard error. The results were analyzed by analysis of variance (ANOVA); completely randomized design, and treatment differences were identified by the method of Newman-Keuls. $\mathrm{P}<0.05$ was determined as the criterion for significance. Five animals were used in each treatment group.

\section{Results}

A dose-dependent increase in biochemical parameters was observed in $\mathrm{CdCl}_{2}$-treated samples in comparison with the controls. $\mathrm{ZnCl}_{2}$ had no effect on blood biochemical parameters; however, pretreatment of rats with $\mathrm{ZnCl}_{2}$ markedly reduced all biochemical parameters in animals treated with various doses of $\mathrm{CdCl}_{2}$. A dose-dependent increase in BUN and $\mathrm{Cr}$ concentration was observed after treating animals with $\mathrm{CdCl}_{2}$ in comparison to control values. Elevation of renal biochemical parameters were predominant in $3-\mathrm{mg} / \mathrm{kg} \mathrm{CdCl}{ }_{2}$-treated rats (Figure 1 and Figure 2).

When compared to control animals, $\mathrm{ZnCl}_{2}$ had no effect on BUN and $\mathrm{Cr}$; however, the levels of biochemical parameters were markedly decreased in pretreated animals in comparison to control rats (Figure 1 and Figure 2). Administration of vehicle alone did not produce de- tectable alteration in MDA level in rat kidney; however, dose-dependent MDA reduction was observed in rats pretreated with $\mathrm{ZnCl}_{2}$ that had received the same dose of $\mathrm{CdCl}_{2}$ (Figure 3).

Figure 1. Effect of Zinc Chloride on Blood Urea Nitrogen in Cadmium Chloride-Treated Rats

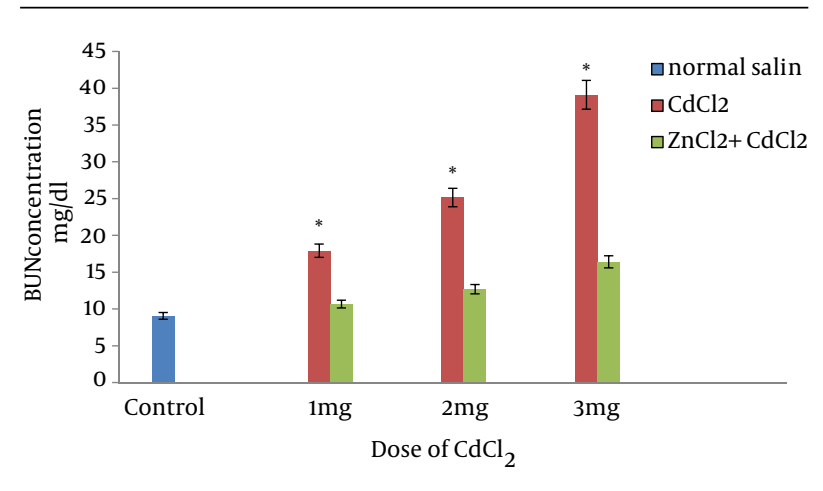

* Significantly different values of blood urea nitrogen (BUN) from rats pretreated with zinc chloride $\left(\mathrm{ZnCl}_{2}\right)$ before receiving the same dose of cadmium chloride $\left(\mathrm{CdCl}_{2}\right)(\mathrm{P} \leq 0.05)$.

Figure 2. Effect of Zinc Chloride on Creatinine in Cadmium ChlorideTreated Rats

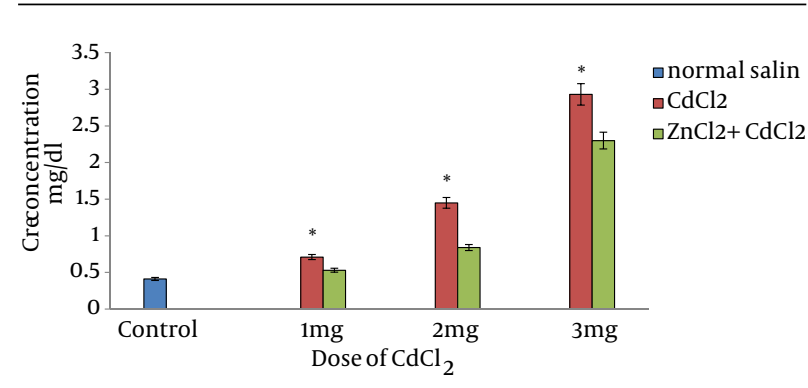
* Significantly different from rats pretreated with zinc chloride $\left(\mathrm{ZnCl}_{2}\right)$
and were given the same dose of cadmium chloride $\left(\mathrm{CdCl}_{2}\right)(\mathrm{P} \leq 0.05)$.

Figure 3. Effect of Zinc Chloride on Malondialdehyde in Cadmium Chloride-Treated Rats Kidney

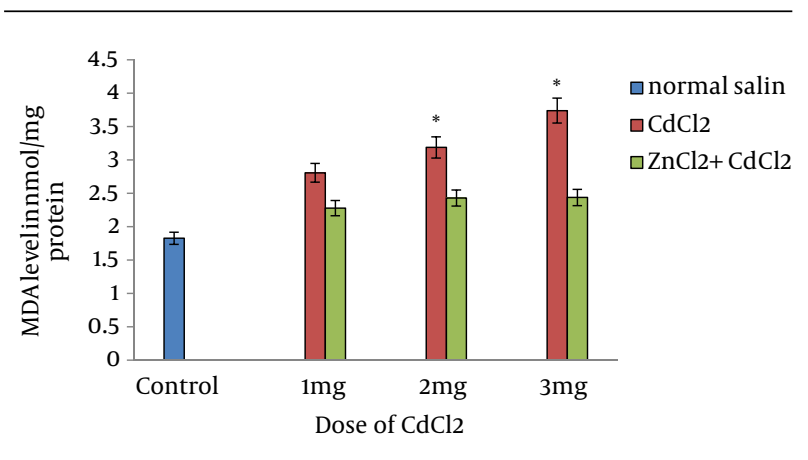

\footnotetext{
* Significantly different values of malondialdehyde (MDA) from rats pretreated with zinc chloride $\left(\mathrm{ZnCl}_{2}\right)$ and were given the same dose of cad mium chloride $\left(\mathrm{CdCl}_{2}\right)(\mathrm{P} \leq 0.05)$.
} 
Morshedi R et al.

\section{Discussion}

Generally, Cd is ubiquitous and due to the increasing industrial use of $\mathrm{Cd}$, evaluation of toxic potentials of this metal is important for the risk assessment of those ordinarily exposed to it. Cd accumulates mainly in the kidney and liver; these two organs are critical targets for acute Cd toxicity (6-8). High doses of Cd administered to experimental animals lead to morphological and functional changes in the liver (11). The kidneys are the major sites of antagonistic interactions of essential elements including $\mathrm{Zn}$ with $\mathrm{Cd}$; therefore, it is a target organ for Cd toxicity. Long-term exposure to even low levels of $\mathrm{Cd}$ leads to kidney damage characterized by tubular dysfunction (16). Moreover, long-term Cd exposure leads to bone lesions (osteoporosis and osteomalacia) in human and experimental animals (17). We found dose-dependent Cdinduced nephrotoxicity in rat, which was indicated by elevation of BUN and Cr. Al-Attar reported that Cd caused significant increase in $\mathrm{Cr}$ and urea concentrations (18). Cd has been reported to cause damage to lipids and hence, lipid peroxidation (19). Accordingly, exposure to Cd led to an increase in MDA concentration in our study. Short-term and long-term $\mathrm{Cd}$ administrations caused damage to the organs, particularly the liver and kidney; it was indicated by an increase in organ MDA levels, which is an indicator of oxidative stress (20). Patra et al. reported that administration of $0.5-\mathrm{mg} / \mathrm{kg} \mathrm{CdCl}$ to rats for three months led to increased MDA levels (21). Koyu et al. have reported that $\mathrm{Cd}$ had caused an increase in MDA level in comparison to controls (22). We showed that the level of MDA was increased after seven days of treatment with 1, 2, and $3 \mathrm{mg} /$ $\mathrm{kg}$ of $\mathrm{CdCl}_{2}$ in comparison to control rats. Erdogan et al. have reported increased plasma levels of MDA in response to $\mathrm{Cd}$ (23). It seems that $\mathrm{Cd}$ enhances oxidative stress and has similar effects on both plasma and kidney MDA.

We observed that Zn protected rat kidney against Cd-induced nephrotoxicity. Similarly, another study reported that $\mathrm{Zn}$ had protected bone against toxicity of $\mathrm{Cd}$ (23). To our knowledge, the effect of $\mathrm{Zn}$ on Cd-induced alterations of renal biochemical parameters had not been reported yet. Our finding was the first report from an in vivo study that provided evidence for beneficial effects of $\mathrm{Zn}$ on the kidneys that were exposed to $\mathrm{Cd}$. Intraperitoneal or subcutaneous Cd-Zn coadministration to prevent or reduce toxic effects of $\mathrm{Cd}$, including hepatotoxicity, nephrotoxicity, carcinogenesis, and mortality, were reported (24). Zn is known to induce the expression of Mt, which may act as an antioxidant (25). Moreover, Mt plays an important role in the metabolism and toxicity of Cd (26). A study reported the protective role of $\mathrm{Zn}$ against Cd-induced histopathologic changes in rat kidney, liver, and lung tissues (24). In conclusion, the present study demonstrated that, $\mathrm{Zn}$ protects kidney against $\mathrm{Cd}$-induced biochemical changes in rats.

\section{Acknowledgements}

The source of data used in this paper was from mas- ter thesis of Raziyeh Morshedi, student of Occupational Health Engineering Department, School of Health, Ahvaz Jundishapur University of Medical Sciences, Ahvaz, Iran.

\section{Authors' Contributions}

Raziyeh Morshedi was responsible for doing the project (related to her MSc thesis); Massumh Ahmadizadeh, supervised the project; Kambiz Ahmadiangali was responsible for data analyses.

\section{Funding/Support}

This study was supported by Physiology Research Center and the Research Deputy of Ahvaz Jundishapur University of Medical Sciences (Grant No. PRC-151).

\section{References}

1. Godt J, Scheidig F, Grosse-Siestrup C, Esche V, Brandenburg P, Reich A, et al. The toxicity of cadmium and resulting hazards for human health.J Occup Med Toxicol. 2006;1:22.

2. DN W. Cadmium - Marked trends and influences. In: 87th proceedings of the 6th International Cadmium conference. editor. Cadmium. London: Cadmium Association; 1988. pp. 9-16.

3. Wang B, Luo Q, Shao C, Li X, Li F, Liu Y, et al. The late and persistent pathogenic effects of cadmium at very low levels on the kidney of rats. Dose Response. 2013;11(1):60-81.

4. Jarup L, Alfven T. Low level cadmium exposure, renal and bone effects--the OSCAR study. Biometals. 2004;17(5):505-9.

5. Zalups RK, Ahmad S. Molecular handling of cadmium in transporting epithelia. Toxicol Appl Pharmacol. 2003;186(3):163-88.

6. World Health Organization. Environmental Health Criteria 134. Geneva: WHO; 1992. Available from: http://apps.who.int/iris handle/10665/38998.

7. Casalino E, Calzaretti G, Sblano C, Landriscina C. Molecular inhibitory mechanisms of antioxidant enzymes in rat liver and kidney by cadmium. Toxicology. 2002;179(1-2):37-50.

8. Jarup L. Cadmium overload and toxicity. Nephrol Dial Transplant. 2002;17 Suppl 2:35-9.

9. Swiergosz-Kowalewska R. Cadmium distribution and toxicity in tissues of small rodents. Microsc Res Tech. 2001;55(3):208-22.

10. Karabulut-Bulan O, Bolkent S, Yanardag R, Bilgin-Sokmen B. The role of vitamin $\mathrm{C}$, vitamin $\mathrm{E}$, and selenium on cadmium-induced renal toxicity of rats. Drug Chem Toxicol. 2008;31(4):413-26.

11. Brzoska MM, Moniuszko-Jakoniuk J. Interactions between cadmium and zinc in the organism. Food Chem Toxicol. 2001; 39(10):967-80.

12. Gurbay A. Protective effect of zinc chloride against cobalt chloride-induced cytotoxicity on vero cells: preliminary results. Biol Trace Elem Res. 2012;148(1):110-6.

13. Rafique M, Pervez S, Tahir F. Protective effect of zinc over lead toxicity on testes. J Coll Physicians Surg Pak. 2010;20(6):377-81.

14. Jemai H, Lachkar HA, Messaoudi I, Kerkeni A. Effects of zinc pretreatment on blood glutathione, serum zinc and kidney histological organisation in male rats exposed to cadmium. J Trace Elem Med Biol. 2010;24(4):277-82.

15. Satoh K. Serum lipid peroxide in cerebrovascular disorders determined by a new colorimetric method. Clin Chim Acta. 1978;90(1):37-43.

16. Jarup L, Berglund M, Elinder CG, Nordberg G, Vahter M. Health effects of cadmium exposure--a review of the literature and a risk estimate. Scand J Work Environ Health. 1998;24 Suppl 1:1-51.

17. Brzoska MM, Moniuszko-Jakoniuk J. The influence of calcium content in diet on cumulation and toxicity of cadmium in the organism. Arch Toxicol.1998;72(2):63-73.

18. Al-Attar AM. Antioxidant effect of vitamin E treatment on some heavy metals-induced renal and testicular injuries in male mice. Saudi J Biol Sci. 2011;18(1):63-72.

19. Rikans LE, Yamano T. Mechanisms of cadmium-mediated acute hepatotoxicity. J Biochem Mol Toxicol. 2000;14(2):110-7. 
20. Esrefoglu M, Gul M, Dogru MI, Dogru A, Yurekli M. Adrenomedullin fails to reduce cadmium-induced oxidative damage in rat liver. Exp Toxicol Pathol. 2007;58(5):367-74.

21. Patra RC, Swarup D, Senapati SK. Effects of cadmium on lipid peroxides and superoxide dismutase in hepatic, renal and testicular tissue of rats. Vet Hum Toxicol.1999;41(2):65-7.

22. Koyu A, Gokcimen A, Ozguner F, Bayram DS, Kocak A. Evaluation of the effects of cadmium on rat liver. Mol Cell Biochem. 2006;284(1-2):81-5.

23. Erdogan Z, Erdogan S, Celik S, Unlu A. Effects of ascorbic acid on cadmium-induced oxidative stress and performance of broilers. Biol Trace Elem Res. 2005;104(1):19-32.

24. Jemai H, Messaoudi I, Chaouch A, Kerkeni A. Protective effect of zinc supplementation on blood antioxidant defense system in rats exposed to cadmium. J Trace Elem Med Biol. 2007; 21(4):269-73.

25. Kagi JH. Overview of metallothionein. Methods Enzymol. 1991;205:613-26.

26. Il'yasova D, Schwartz GG. Cadmium and renal cancer. Toxicol Appl Pharmacol. 2005;207(2):179-86. 